FINITE ELASTOPLASTIC DEFORMATIONS : BASIC CONCEPTS AND APPLICATIONS

\author{
Guillermo J. Creus \\ Department of Civil Engineering \\ Universidade Federal do Rio Grande do sul \\ Porto Alegre, RS, Brasil
}

\title{
RE SUMEX
}

\begin{abstract}
Este trabajo analisa la representación del comportamien to mecánico (isotérmico) de sólidos elastoplásticos con grandes deformaciones elasticas y plasticas y anisotropía en el rango plástico. Estado y orientación de elementos descargados son descritos por medio de tensores de rango irreducible. Es incluida la discusión de algunas dificultades usuales en analisis con grandes deformaciones así como aplicaciones de un programa de elementos finitos.
\end{abstract}

\section{ABSTRACT}

The paper is concerned with the representation of isothermal mechanical behavior of an elastoplastic solid that possesses finite elastic range and exhibits anisotropy in its plastic behavior. The state and orientation of a stress free element is described by means of irreducible rank tensors. A discussion of some difficulties usual in finite strain analysis and applications using finite elements are included. 


\section{INTRODUCTION}

In this work we describe some applications of the finite elements nethod to elastoplastic problems in the presence of finite strains. We consider inviscid plasticity and incremental (rate) solutions; this approach has been the most popular for the solution of practical problems because, by reducing the nonlinear problem to a series of linear associated problems, it can take advantage of available a 1 gorithms and softuare. Important alternatives not considered here are the viscoplastic formulations $|1|,|2|$ and solutions by direct minimization of the functional relations $|3|,|4|$. The relatively new technique of boundary elements has been already applied to plasticity problems |5| and may have advantages in some situations. On the other hand, most of the results described here for constitutive modelling in the presence of finite strains should be valid for any solution procedure.

We begin this paper by recalling, in section 2, some well-known results from small deformations plasticity theory. Then, in Section 3 we indicate an extension to the range of finite elastic and plastic deformations. As it is vel1-known, elastic deformations of ductile metals are bound to be small because of the relation between yield stress and elastic modulus. Nevertheless, the consideration of finite elastic deformations is important from a theoretical point of viev and has already some applications for new synthetic macerials $|6|$. In Section 4 this formulation is illustrated through examples for frame and continuous structures. Soae applications to geomaterials and aetalworking processes are discused in section 5 .

Our work at the curso de Pós-Graduação em Engenharia Civil, UFRGS, has been a joint effort with E.T.Onat from Iale University and A.G.Groehs. Some numerical results were taken from MSc. dissertions of our students, as indicated ia the references. The research progran was initiated under the coordination of A. J.Ferrante.

\section{SMALL DEFORMATIONS FORMULATION}

In order to establish a comon background and notation we begin by reviewing the small deformations theory. The basic relations are:

\section{i) Definition of plastic deformation}

$$
\varepsilon=\varepsilon^{e}+\varepsilon^{P}
$$

where $\varepsilon^{P}$ is the plastic strain and $\varepsilon^{e}$ the elastic (recoverable) one. In incremental plasticity this relation is normally witcen in the rate form $\left.\mid C^{\circ}\right)=\partial / \partial t \mid$

$$
\dot{\varepsilon}=\varepsilon^{e}+\epsilon^{p}
$$

ii) Definition of yield condition

$$
Y(0, s)=0
$$


Eq (3) represents, in the 9-dimentional space $\Sigma$ (whose coordinates are the components of the (Cauchy) stress tensor o), a closed surface that encloses the elastic domain. In general, this surface changes during the elastoplastic deformation process; this change is loosely referred to as hardening. Symbol $S$ in (3) represents set of parameters that characterize the state of the material and models hardening.

iii) Loading-unloading criteria. From (3) we characterize unloading processes with

$$
\dot{\mathbf{Y}}=\frac{\partial \mathbf{Y}}{\partial \sigma} \dot{\sigma}<0
$$

and loading processes with

$$
\dot{\mathrm{Y}}=\frac{\partial \mathrm{Y}}{\partial \sigma} \dot{\sigma}+\frac{\partial \mathrm{Y}}{\partial S} \dot{S}=0 \quad ; \quad \frac{\partial \mathrm{Y}}{\partial \sigma} \dot{\sigma} \geqslant 0
$$

In the second (5) sign $\Leftrightarrow$ corresponds to neutral loading that does not modify the material's state and ( $>$ ) to active loading. The differentiation indicated in (4), (5) assumes that the yield surface is smooth; al ternative formulations can be considered for yield surfaces with corners |7|.

iv) Incremental elastic relation:

$$
\dot{\varepsilon}^{e}=\mathrm{E}^{-1} \dot{\sigma}
$$

where $E$ is the elastic isotropic constitutive matrix.

v) Incremental relation for the plastic deformation

$$
\dot{\varepsilon}^{p}=\dot{\Lambda} \frac{\partial g}{\partial \sigma}\left(\frac{\partial Y}{\partial \sigma} \dot{\sigma}\right) ; \dot{\Lambda} \geqslant 0
$$

where $g(\sigma, S)$ is scalar function termed plastic potential; the term ( $\partial Y / \partial \sigma . \dot{\sigma})$ assures continuity for neutral loading. relation

Fron (2), (5), (6), (7) we obtain the elastic constitutive

$$
\dot{\sigma}=E_{e p} \dot{\varepsilon}
$$

where

$$
E_{e p}=E-\frac{E \bar{a} a^{T} E}{A+a^{T} E a}
$$

being

$$
a=\frac{\partial Y}{\partial \sigma} \quad ; \quad \bar{z}=\frac{\partial g}{\partial \sigma} ; A=-\frac{1}{\delta} \frac{\partial Y}{\partial \sigma} \cdot S
$$

Relation (9), first proposed by Hill |8| was rediscovered by Yamada $|9|$.

\section{FINITE STRAIN FORMULATION}

In this section we shall limit ourselves to review only some important points. stresing the differences between 
small and large strain theories. A more detailed explanation can be found in the references given.

\subsection{Kinematics}

For finite train we must obviously abandon the usual linearized definition of specific deformation $E$. Many alternatives have been proposed $|10|,|11|,|12|$, but it appears that, as in finite elasticity, it is convenient to begin with the deformation gradient F, such that the relation

$$
x=F(t) x ; t \in[0, \infty)
$$

indicates that $P(t)$ carries the material point $x$ from its position $x$ in $t=0$ to the position $x$ in $t$. For the deformations considered det $F(t)>0$. During the deformation process a cubic element is transformed into a parallelepiped whose shape is characterized by F F. For rigid body rotations we have naturally F=I and det F=l.

In the elastoplastic case ve define plastic deformationa through the decomposition $|13|$

$$
F=F_{e} F_{p}
$$

This decomposition is made unique by choosing $|14|$

$$
F_{e}=F_{e}^{T}
$$

Frov (11) we nay write

$$
\dot{F}(t)=\frac{d}{d t} F(t)=F(t) F^{-1}(t)=D+\Omega
$$

where $D=D^{T}$ is the rate of strain and $\Omega=-\Omega^{T}$ is the rate of rotation. We can define the corresponding elastic and plastic entities in the form

$$
\begin{aligned}
& \dot{F}_{p} F_{p}^{-1}=D_{p}+\Omega_{p} \\
& F_{e} F_{e}^{-1}=D_{e}+\Omega_{e}
\end{aligned}
$$

and observe that it is

$$
D+\Omega=D_{e}+\Omega_{e}+F_{e}\left(D_{p}+\Omega_{p}\right) F_{e}^{-1}
$$

Thus, when elastic strains are small, so that ve can cake $F_{e}=I(16)$ yields

$$
\begin{aligned}
& D=D_{e}+D_{p} \\
& \Omega=\Omega_{e}+\Omega_{p}
\end{aligned}
$$

The first ( 17$)$ is (increaentally) equivalent to (2).

In the general case ve can find form more convenient than (16). Defining elastic strain through the left CauchyGreen train tensor

$$
B_{e}=F_{e} e^{T}=F_{e}{ }^{2}
$$


and the nev measure of plastic strain $\hat{D}_{p}$ with

$$
\begin{gathered}
\hat{D}_{p} B_{e}+B_{e} \hat{D}_{p}=2 F_{e} D_{p} P_{e} \\
\hat{D}_{p}=\hat{D}_{p} T
\end{gathered}
$$

we obtain

$$
\begin{gathered}
\dot{B}_{e}=\left(D-\hat{D}_{p}+\Omega\right) B_{e}+B_{e}\left(D-\hat{D}_{p}-\Omega\right) \\
\Omega-\Omega_{p}=W\left(D+D_{p}\right)
\end{gathered}
$$

where $W$ is a linear mapping that depends on $F_{\text {. }}$

Eq. (2) is the finite strain equivalent of (2) and keeps the additive patern. Eq. (2l) tells us that once $D$, ${ }_{p}$ and $\Omega$ are given $\Omega_{p}$ is determined.

\subsection{Elastic relations}

We consider the elastic constitutive relations for an elastic material which is isotropic in the elastic range. In this case it exists a train energy function $\psi$ per unit mass

$$
\downarrow=\psi\left(I_{1}, I_{2}, I_{3}\right)
$$

where

$$
I_{i}=\operatorname{cr}\left(B_{e}^{i}\right)
$$

are the basic invariants of the left Cauchy-Green tensor B. The corresponding Cauchy stress 0 is obtained from (22) and the relation

$$
\sigma \cdot D=p
$$

in the form

$$
\sigma=2 \rho\left(\frac{\partial \psi}{\partial I_{1}} B_{e}+2 \frac{\partial \psi}{\partial I_{2}} B_{e}^{2}+3 \frac{\partial \psi}{\partial I_{3}} B_{e}^{3}\right)
$$

where $p$ is the current density of the material. Using the continuity relation

$$
\dot{\rho}+\rho \operatorname{tr} D=0
$$

and noticing that from (23) it is

$$
i_{i}=2 i B_{e}^{i}\left(D-\hat{D}_{p}\right)=2 i \operatorname{trB}{ }_{e}^{i}\left(D-\hat{D}_{p}\right)
$$

we obtain

$$
\dot{\sigma}=-\sigma \operatorname{tro}+\left(D-\hat{D}_{p}+\Omega\right) \sigma+\sigma\left(D-\hat{D}_{p}-\Omega\right)+\bar{E}\left(D-\hat{D}_{p}\right)
$$

where 


$$
\begin{aligned}
& \bar{E}_{i j k l}=2 p\left[2 \psi_{, 2}\left(B_{i k} B_{1 j}+B_{1 j}+B_{i 1} B_{k j}\right)+\right. \\
& +3 \psi,{ }_{3}\left(B_{i k}^{2} B_{1 j}+B_{i k} B_{1 j}^{2}+B_{j l}^{2} B_{k j}+B_{i l} B_{k j}^{2}\right)+24,11 B_{i j} B_{k l}+ \\
& +4 \psi, 12\left(B_{i j} B_{k l}^{2}+B_{i j}^{2} B_{k 1}\right)+8 \psi, 22\left(B_{i j}^{2} B_{k 1}^{2}\right)+ \\
& \left.+12 \psi, 2,\left(B_{i j}^{2} B_{k 1}^{3}+B_{i j}^{3} B_{k 1}^{2}\right)+18 \psi, 3, B_{i j}^{3} B_{k 1}^{3}\right]
\end{aligned}
$$
deformations are isochoric, i.e. $\operatorname{tr} \mathrm{D}_{p}=0$ and thus (28) can be written

$$
\dot{\sigma}=\Omega \sigma-\sigma \Omega+\hat{E}\left(D-\hat{D}_{p}\right)
$$

3.3. State and orientation of stress-free previousiy deformed elements

As seen in section 3.1 we may unload plastically deformed element applying deformation $F^{-1}$. The previous plastic deformation has produced some changes in the material's internal structure that may be represented using the concept of state $|14,15|$. The sate $S$ can be characterized by $n$ parameters

$$
s=\left(q_{1}, \ldots q_{n}\right)
$$

It can be shown $|16|$ that the $q_{i}{ }^{\prime} s$ must be irreducible even rank tensors.

We are also interested in the growth 1 aw for $S$ and in particular in its dependence on rotation which is important in the case of materials that develop anisotropy during a deformation process with finite strains and rotations. A rigid body rotation of the material element represented by $Q \in 0^{+}(3)$ causes the state point to move to

$$
P_{Q} S=\left(P_{Q^{Q}}, \cdots, P_{Q} q_{N}\right)
$$

where $P$ represents an ordinary tensor transformation adequate to the rank of $q_{i}$. As for the growth of $S$ we can wite, for a rotation $\Omega$,

$$
\frac{d S(t)}{d t}=A(S, \sigma, D)-T_{W D} S+T_{\Omega} S
$$

where $T_{\Omega}$ is a linear mapping on $R^{n}$ that depends linearly on $\Omega$. A more detailed explanation may be found in refs. $|17|$. $|18|$.

3.4. Some fine points to be careful about

i) When linearized stress o and linearized a are used in the classical infinitessimal theory it is certainly correct to calculate for incremental loading the corresponding stress increment $\Delta \sigma$ and add these stress increments in order to obtain an approximate expression for the stresses. For finite deformations, hovever, this wust be done with 
care, keeping in wind that stresses can be added only if they are referred to and measured per unit area of the sane reference configuration.

ii) Tield conditions wust be witcen in terms of cauchy tress which is the only one with real physical weaning. It is unacceptable to wite yield conditions in terms of (for instance) the second Piola-kirchhoff stress, that depends on an (arbitrary) initial configuration definition.

iii) In classical plasticity theory plastic deformations are assumed isochoric. In the case of small elastic and large plastic strain, total deformation is mostly incompressible. That is, the material behaves as if havinga shear modulus auch higher than the shear modulus. This type of behavior may give rise to important errors when working with some finite element types and meshes $|19|,|20|$.

Let us consider the four-nodes isoparametric element shown in Fig. 1 for the case of an equivolumetric deformation. With this type of element it is normal to use $2 \times 2$ Gauss integration to calculate the stiffness. For this situation we have volume increase around two integration points and volume decrease in the other two. As the material is almost incompressible these (opposite) changes of volune give rise to important stresses and the tiffness obtained results larger than the real one.

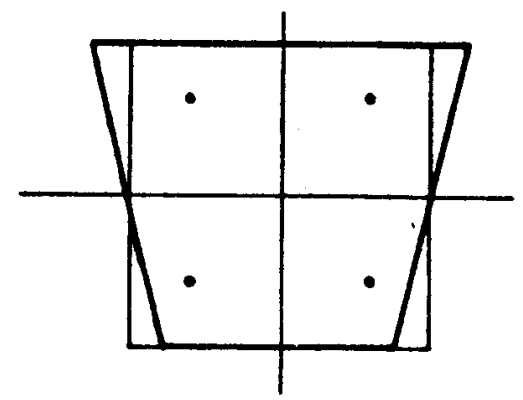

Fig. 1

A way out for this problem was proposed by Nagtegaal et al $|19|$ using ideas already proposed by Herrmann $|21|$ and Key $|22|$. It consists in defining a new degree of freedom for the volumetric train. This procedure leads to modification of the basic variational principle. From Fig. 1 it is also apparent that the problem may be avoided using (in the present situation) a single integration point at the center of the element. This observation leads to the method of reduced integration proposed by zienkiewicz $|23|$ in order to introduce a singulerity in the volumetric component of the tiffness watrix. In the case of the linear element this method is not adequate because reduced integration leads frequenty to a singularity also for the tangencial stiff- 
ness |24|. In ESFINGE $|20|,|25|$ we have used the modified functional formulation for linear elements and reduced integration for quadratic elements. Fig. 2 shows an example comparing ESFINGE with compresible and incompressible

elements and numerical and experimental results from ref. $|26|$, indicated by (H). The error becomes much larger for finite deformations.

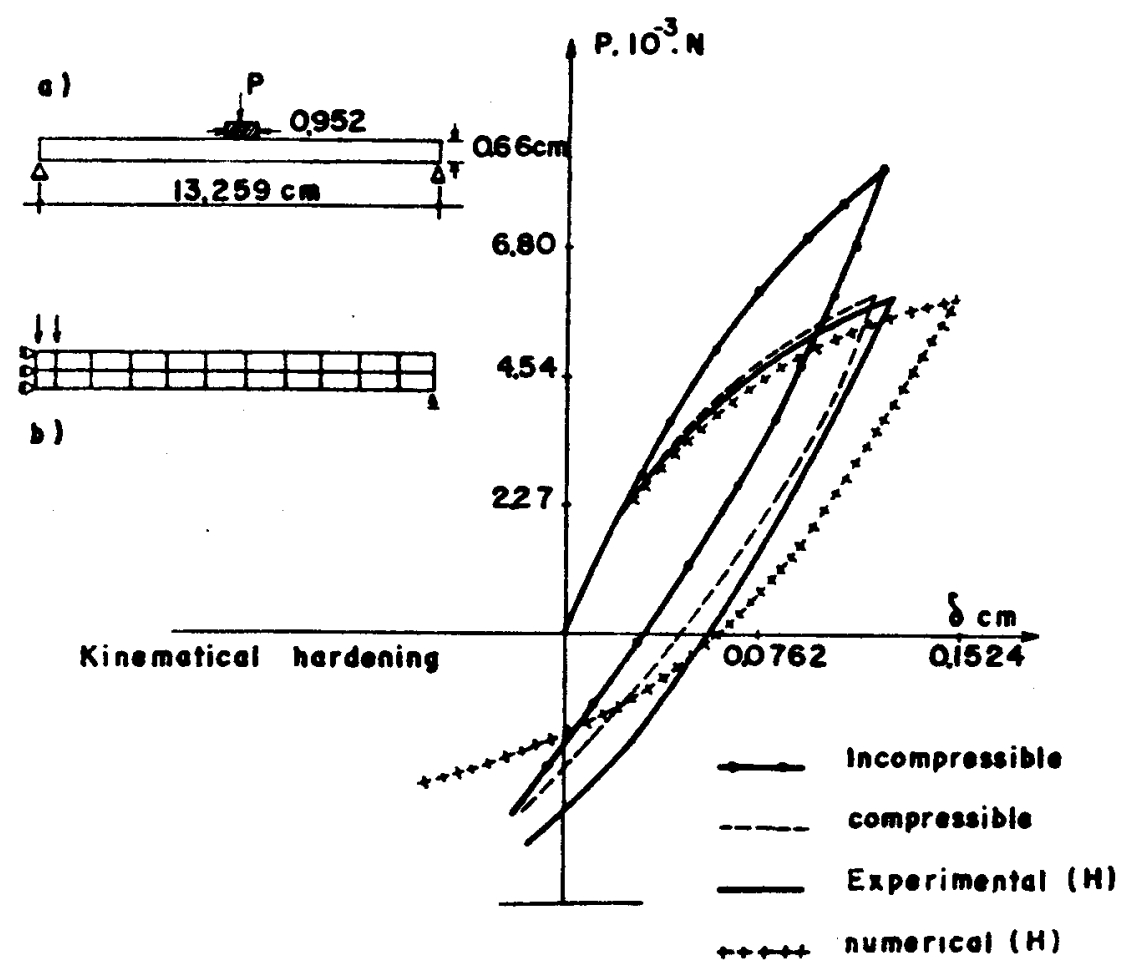

Fig. 2

iv) Computer studies by Nagtegal and de Jong $|27|$ have shown some surprising results in the analysis of large plastic deformations of kinematically hardening materials. These results show oscillating stresses under monotonically increasing strains. We vill look at the problen following. simplified analysis by Onat $|28|$.

We consider a werial element under simple shear. Fig. 3. The corresponding values of the rates of strain and rotation are

$$
D-\left|\begin{array}{lll}
0 & 1 & 0 \\
1 & 0 & 0 \\
0 & 0 & 0
\end{array}\right| \quad ; \quad \Omega=\left|\begin{array}{rrr}
0 & 1 & 0 \\
-1 & 0 & 0 \\
0 & 0 & 0
\end{array}\right|
$$



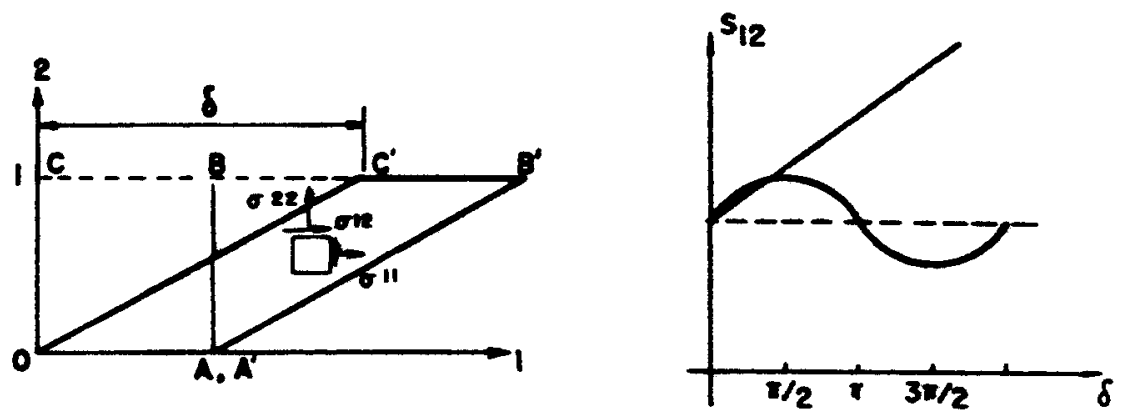

Fi. $\cdot 3$

We consider a rigid-perfectly plastic aaterial with kinematic hardening

$$
I(\sigma, s)=\frac{1}{2}(s-\alpha)(s-\alpha)-k^{2}
$$

where is the deviatoric stress

$$
\text { - } \sigma-\frac{1}{3}(\operatorname{tro} \sigma
$$

Using the associated flow rule

$$
\text { D } \lambda^{2 \mathrm{~T}} / 2 \theta-\lambda(s-\alpha)
$$

we obtain

$$
=a+\sqrt{2} \times \frac{D}{\sqrt{D \cdot D}}
$$

The growth lav for a can be written in general (see 33)

$$
\dot{a}=\lambda \mathrm{A}(s, a)+a-\alpha \Omega
$$

Prager's rule is a particular case of (39) with

$$
\dot{a}=\lambda_{s}(s-a)+\Omega a-a \Omega
$$

Integrating ( 40 ) for the shear problen (34) and substituting into (38) we obtain

$$
B_{12}=\sigma_{12}=k+\frac{1}{2} \text { sen } 8
$$

an oscillating stress as shown in Fig. 3, where one would expect an ever increasing stress. This behavior is caused by the rotation terms in dominate expression (40) and can be corrected with a beter choice of $A$ in (39). Onat proposes

$\dot{\alpha}=a+[\Omega+c(D a-\alpha D)] \alpha-a[\Omega+c(D a-\alpha D)] ; \quad a>0 ; \quad c>0$

The interplay of parameters and c allows the lodeling of - large variety of responses. The most adequate values have to be deterained by experinents. 


\section{APPLICATIONS}

\subsection{Frame structures}

One of the simplest applications corresponds to frame structures. The results are useful per se and from a didactical point of view.

Elastic relations: we must make some simplifying assumptions in order to obtain the usual nonlinear expressions corresponding to small deformations and large rotations. Thus, we disregard specific deformations in relation to rotations, writing

$$
D+\Omega=\Omega
$$

Moreover, we consider that the nost important component of the stress state in relation to the nonlinear behavior is the axial stress

$$
\sigma=N / A ; A \text { : element area }
$$

With these simplifying assumptions, the element stiffness matrix reduces to a form

$$
K=\int_{v_{e}}\left(B^{T} E B+\frac{n}{A} \bar{x}^{T} \bar{y}\right) d V
$$

where $B$ and $\bar{N}$ are the matrices used to calculate strain gradient $D$ and velocity gradient $D+\Omega$ respectively from the node velocities.

Using ( 45 ) and the interpolation functions corresponding to simple beam theory we obtain

$$
K=R_{L}+R_{K L}
$$

$R_{\text {and }} R_{\text {are }}$ respectively the linear and nonlinear (or geometrical or initial stress) stiffness matrices. The condition

$$
\text { det }\left(R_{L}+k_{N L}\right)=0
$$

is used to determine the load corresponding to elastic instability, $|23|$.

Plastic relations: to establish the plastic relations we need aield function $Y$ adequate for the problem; For plane frames, this relation may be written $|29|,|30|$

$$
Y=\left(\frac{F_{x}}{N_{p}}\right)^{\alpha}+\left(\frac{F_{y}}{Q_{p}}\right)^{\beta}+\frac{\left|M_{z}\right|}{M_{p}}-1-q=0
$$

where $N_{p}, Q_{p}$, $M_{p}$ are the limit plastic values for normal force, Sheaf folce and moment for the given section. This yield function represents the behavior of many simmetric metallic sections for adequate values of a and $B$. The state variable a ma be used to model isotropic hardening. He may found in the literature yield functions for many sections, 
including reinforced concrete $|31|,|32|$ and thin-walled metallic section $|33|$.

The elastoplastic matrix E is obtained using the same procedure as indicated in Sectioh $3,|30|$. Naturaliy, when we use the simplifyed plastic relation

$$
\frac{|M|}{M_{p}}-1=0
$$

we obtain the stiffness matrix corresponding to a bar with bending moment discontinuity that corresponds to the classical plastic hinges analyses. The use of the generalized yield function (48) is mandatory whenever normal and shear forces are important. This is the case with arches and with some large deformations situations $|35|,|29|$.

\subsection{Metal forming problews}

One of the most promising fields for the application of finite strains elastoplastic analysis is probably the study of metal forming processes. In the past, approximate methods have beea developed and used for several fabrication processes, based on the hipothesis of rigid-plastic materials without hardening $|8|$. These methods are useful to predict deformation loads, approximate global deformations and qualitative models of plastic flow. But we cannot control che effects of friction and hardening neither determine the internal stresses generated during the deformation process.

Only after the development of the finite elements technique it begun to be possible a more precise determination of these effects and the role played by the different parameters.

Fig. 4 indicates the results of the numerical analysis using ESFINGE $|35|$, with experimental results |36| for an upsetting process. We see that the approximation is fairly good even for finite deformations.

A difficult question in the analysis of metal forming is the adequate representacion of unilateral contact and friction. A promissing approach has been proposed in ref. $|37|$ that we shortly review in the following section.

Unilateral contact and friction analysis: the problem of unilateral contact may be expressed

$$
\Delta u_{n}-\Delta_{B_{n}}=0 \quad \text { on } r_{c}
$$

where $\Delta u_{n}$ is the increment of the normal displacement constrained by a given motion $\Delta_{g_{n}}$ on the contact surface $\Gamma_{c}$. The constraint (50) may be approximated by analty condition $|38|,|39|$

$$
k\left(\Delta u_{n}-\Delta_{B_{n}}\right)=0
$$

where $k$ is auch larger than the element stiffness. Physically, this can be interpreted as adding to the degree of 

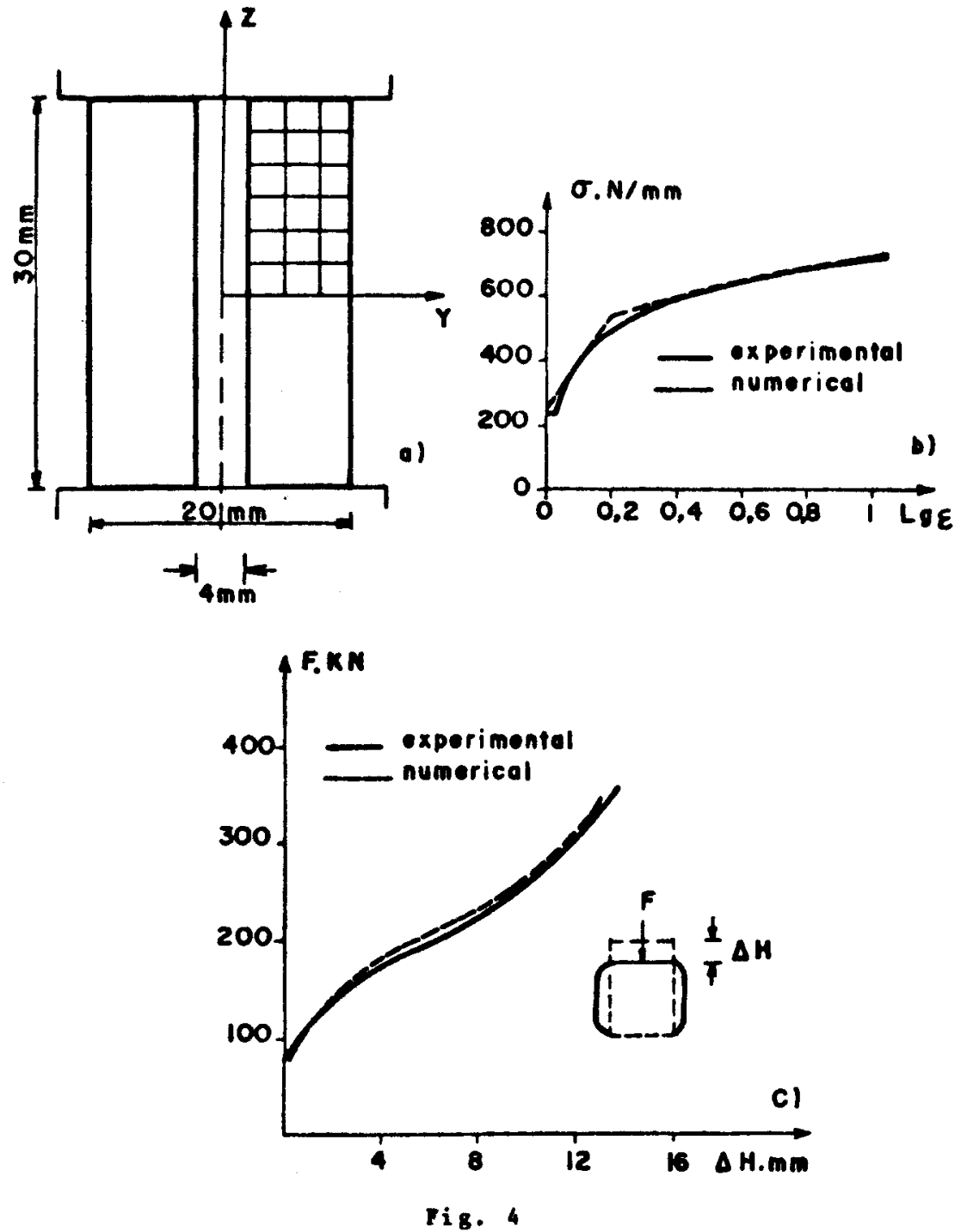

freedom $i$ spring of large stiffness k and specifying a load which because of the relative rigidity produces the required displacement $\Delta_{g_{n}}$. This procedure way eventually introduce large off-diagonal terms into the siffness matrix, diminishing the olution accuracy, |40|. A different approach may be found in $|41|$.

For the friction problea, we may asume that there exists a Coulomb isotropic sip function $|37| .|42|$

$$
f={\sqrt{t_{T} \cdot t_{T}}}_{\mathrm{f}}+\mu_{\mathbf{T}} \cdot t_{\mathrm{n}}
$$

where $t_{T}$ and $t_{n}$ are the tangencial and normal components of 
the stress at the contact region. The situation of non-aliding and sliding way then be witten as the conditions for loading in the general plastic case (section 3 )

$$
\begin{array}{r}
f<0 ; \Delta t_{T}=-k_{T}\left(\Delta u_{T}-\Delta g_{T}\right) \\
f=0 ; \quad ;=0 ; \Delta u_{T}=-\Lambda \frac{\partial E}{\partial t_{T}}
\end{array}
$$

Using (52), (53), (54) we can determine relations similar to a normal elastoplastic relation. The functional relation used in the finite elements formulation must naturally be completed with the work performed by the contact stess vector during the sip.

Plastic behavior of geomaterials: the analysis of elastoplastic behavior of geomaterials is a field of growing interest; for a recent review see for example |43|. One important problea concerns the failure behavior of soft rock wasses in relation to the construction of tunnels and the excavation of mines $|44|$, which is strongly related to negative hardening (or softening) in the plastic range.

The simplest approach to softening behavior uses the same formulation of classical plasticity and a negative hardening parameter, $|45|,|23|$. In Fig. 5 we may see some results corresponding to thick valled tube under external pressure in a plane strain condition |46|; the variation of radial stress $\sigma_{x}$ and circunsferential stess $\sigma_{y}$ is shown for three characteristic stages. Strain softening produces. concentration of stress in an outer ring in a tace close to three-axial loading. Stresses are very low in the already degraded waterial near the central hole. In the load-disple-
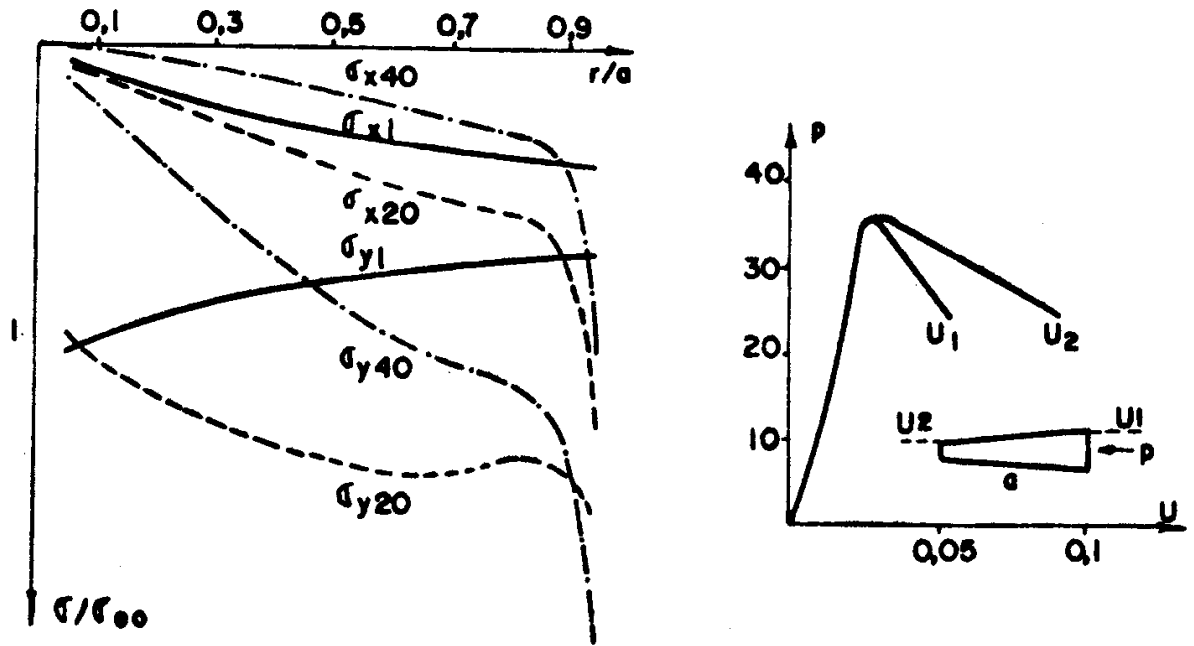

Pis. 5 
cement behavior in Fig. S we may observe the larger displacements corresponding to the elements near the inner edge. This behavior and the general stress distribution seems to represent well that observed for deep tunnels in strainsoftening materials.

The concentration of plastic zones in strain softening bodies is well known phenomenon $|23|,|45|$, and can be physically interpreted. On the other hand, in finite elements analyses it produces numerical instability and sensitivity to mesh size $|23|,|45|,|47|$ that seew unnatural. It has also been stated that dynamic problems with continuous strain softening are not mathematically well posed |48|. Several ways have been already proposed to circunvent these

difficulties: the use of rate dependent (viscoplastic) relations, $|48|$, the consideration of concentrated shear bands $|49|$ and the use of nonlocal theories $|50|$.

\section{RE FE REN CES}

1) Zienkiewicz, 0.C. and Cormeau, I.C., "visco-plasticity and creep in elastic solids" - A unified numerical solution approach, Internat. J. Numer. Meths. Engrg. 8 (1974) 821-845.

$|2|$ Taroco, E., Feijóo, R.A., "Viscoplasticity, variational formulation" (in Portuguese), II Escola de Matemática Aplicada, LCC-CAPq, Rio de Janeiro, 1980.

3| Maier, G., "Quadratic programing and the theory of elastic-plastic structures", Meccanica, Vol. 13, 1968.

| $4 \mid$ Pereira, M.2., Feijóo, R., Taroco, E. and Bevilacqua, L., "The Limit Analysis of Shells of Revolution using two Finite Element Approaches", IUTAM Symposium on Inelastic Behavior of Plates and Shells, Rio de Janeiro, 1985 .

| $5 \mid$ Telles, J.C.F., Brebbis, C.A., "New Developments in Elastoplastic Analysis", Proc. of the 3rd Int. Seminar on Boundary Elements, Irvine, California (1981), Springer, 350-370.

| 6| Parks, D.M., Argon, A.S. and Bagepalli, B., "Large elastic-plastic deformations ot glassy polymers", Part I: constitutive modelling. Department of Mechanical Engineering Report, K.I.T., Cambridge, MA., 1984

| 7 | Koiter, W.T., "Stress-strain relations, uniqueness and variational theorems for elastic-plastic materials with angular yield surfacen, Quart. Appl. Mach., 11 (1953) $350-54$.

| $8 \mid$ Hill, R., "The Mathematical Theory of Plasticity", oxford Univ. Press, Oxford, 1950.

| $9 \mid$ Yamada, Y. Yoshimura, N. and Sakurai T. "Plastic stress strain matrix and its application for the solution of elastic-plastic probleas by the finite 
eleneat method", Internat. J, Nech. Sei. $10(1967) 343-$ 354.

|10| Mandel, J., "Direction Vectors and Constitutive Equations for Plastic and Visco-plastic media". Problems in Plasticity, Noordhoff, Leyden (1974)135-143.

$|11|$ Green, A.E. and Naghdi, P.K., "som remarth on aleseleplastic deformation at finite stain". Internat. J. Engrg. Sci. 9(1971)1219-1229.

|12| Argyris, J.H. and Kleiber, M., "Incremental formulation in nonlinear wechanics and large train elasto-plasticity - Natural appoach", Part I, Comput. Meths. Appl. Hech. Engrg. 11(1977)213-247. Argyris, J.H., Doltsinis, J.St. and Kieiber, M., Part II, Comput. Meths. Appl. Hech. Engrg. 14(1978) 259-294.

$|13|$ Liu, D.T. and Lee, E.H., "Finite strain elastic-plastic theory". Proc. IUTAM symposium, Vienaa, Springer, Berlin (1966)213-222.

$|14|$ Fardshisheh, F. and Onat, E.T., "Representation of Elastoplastic behavior by means of state variables"., Probleus in Plasticity, Noordhoff, Leyden (1974)89-i is.

|15| Onat, E.I., "Representation of inelastic mechanical behavior by means of state variables", Proc. IUTAM Syap., East Xilbride (1966), Springer'(1968)292-314.

$|16|$ Geary, J.A., Onat, R.T., "Representation of nonlinear hereditary mechanical behavior", Oak Ridge Mational Laboratory Report, ORNL-TM-4525 (1974).

$|17|$ Onat, E.T., Creus, G.J., Groehs, A.G., "Constitutive equations for finite deformations of elastic-plastic solids". Conference on Structural Aaralyis and Design of Power Plants, Porto Alegre (1984).

|18| Groehs, A.G. and Creus, G.J., "Elastoplastic Constitutive Equations used in the program ESFINGE" (in Portuguese), Colloquio 83, Chile (1983).

|19| Nagtegaal, J.C., Parks, D.K. and Rice, J.R., "On numericaliy accruate finite element solutions in the fully plastic range", Computer Meth. in Appl. Mech. and Engr8., 4(2) (1974) 153-177.

$|20|$ Groehs, A.G. and Creus, G.J., "Implementation of isoparametric linear elements into ESFINGE - Part I and I" (in Portuguese), COBEM 83, VII Congresso Brasileiro de Engenharia Mecánica, 1983.

$|21|$ Herrman, L.R., "Elasticity equations of incompressible and nearly incompressible materials by a variational theorea", AIAA J. 3 (1965)1896-1900.

$|22|$ Key, S.W., "A variational principle for incompressible and nearly-incompressible enisotropic elasticity", Int. J. Solids and Structures, 5 (1969)951-964. 
$|23|$ Zienkiewicr, "The Finite Element Method", McGraw-Hill, Hew York, 3rd ed., 1977.

$|24|$ Key, S.W., "Concepts underlying finite elements methods for tructural analysis", Nucl. Eng. Design, 48(I), $(1978), 259-68$.

$|25|$ Dutra, S.C., "Solution of elastoplastic probleas with isotropic and kinematic hardening" (in Portuguese), MSc. Thesis, UFRGS, Porto Alegre (1982).

$|26|$ Hunsaker, B., Heisler, W.B. and stricklin, J.A., "On the use of two hardening rules of plasticity in incremental and pseudo force analyses", in Meeting of the American Society of Mechanical Engineers, Nev York, Dec. 5-10, 1976. Constitutive equations in viscoplasticity: computational and engineering aspects, New York, ASME (1979)139-70.

121| Nagtegaal, J.C. and De Jong, J.E., "Some computational aspects of elastic-plastic large strain analysio", in J.T. Oden, ed., Computacional Methods in Nonlinear Mechanics (Norch-Holland, Ansterdam, 1980) 303-339.

$|28|$ Onat, E.T. "shear flow of kinematically hardening rigid-plestic materials". Mechanics of Materials Behavior, Bd. G.J. Dvorak and R.T. Shield, Elsevier, $(1984), 311-323$.

$|29|$ Creus, G.J., Torres, P.L., Groehs, A.G., "Elastoplastic frane analysis with generalized yield function and finite displacements", Computers and structures, Vol. 18, No. 5, $(1984) 925-929$.

$|30|$ Creus, G.J., Torres, P.L., Groehs, A.G., "Instability and plastic collapse of plane frames with generalized yield function", International Conference: Instability and Plastic Collapse of Structures (1983). Manchester.

|31| Heyman, J., "Plastic Design of Frames", Vol. 2, Cambidge University Press (1971).

$|32|$ Braestrup, M.H., "Ten Lectures on Concrete Plasticity", Dept. Struct. Eng., Technical University of Denmark, (1983).

|33| Gjelsvik, A., "The theory of thin walled bars", John Wiley $(1981)$.

|34| Creus, G.J., Torres, P.L., Groehs, A.G., "Elastoplastic analysis of arches considering finite displacements", (in Spanish), Colloquia $83(1983)$, Chile.

$|35|$ Creus, G.J., Groehs; A.G., "Finite element analysis of anisotropic finite plastic deformations", 21 t. Annual Meeting of the Society of Engineering Science, Blacksburg (1984).

|36| Berbertz, R. "Zur Brauchbarkeit eines sterr-visco- 
plastichen Materialgesetzes bei der Lösung umformtechnischer Probleme mit Hilfe der Finite Elemente Methode". Ph.D. Theses, Technischen Hochschule Aachen (1982).

|37| Cheng, J.R., Kikuchi, N., "An analysis of metal forming processes using large deformation elastic-plastic formulations". Comp. Meth. Appl. Mech. Eng., 49 (1985), $71-108$.

$|38|$ Courant, R., Friedrichs, K. and Lewy, H., "On the partial difference equations of mathematical physics", IBM J. 11 (1967)215-234.

$|39|$ Courant, R., "variational methods for the solutions of problems of equilibrium and vibrations", Bull. Amer. Math. Soc., 49 (1943) 1-23.

$|40|$ Bathe, K.J., Wilson, E.L., "Numerical Method in Finite Elements Analysis", Prentice Hall, (1976).

$|41|$ Barbosa, H.J.C., Feijöo, R.A., "Numerical Algorithms for Contact problems in linear elastostatics". Conference on Structural Analysis and Design of Nuclear Power Plants, (1984), Proc. Vol. 1, 231-244, Porto Alegre.

|42| Fredriksson, B., "Finice element solution of surface nonlinearities in structural mechanics with special emphasis to contact and fracture mechanics problems", Comput. Structures 6 (1976)281-290.

|43| Nemat-Nasser, S., "On finite plastic flow of crystalline solids and geomaterials", Journal of Applied Mechanics, 105 (1983)1114-1126.

$|44|$ Akai, K., Hayashi, M., Nishimatsu, Y., (Eds). Proc. of the International symposium on Weak Rock. Tokio, (1981), A.A. Balkema, Rotterdam.

$145 \mid$ Prevost, J.H.. Höeg, R., "Soil mechanics and plasticity analysis of strainsoftening", Geotechnique, 25 (1975) 279-297

|46| Groehs, A.G., Creus, G.J., "Elastoplastic analysis considering strain-softening behavior" (to be published).

147| Pietruszczak, St., Mróz, 2., "Numerical Analysis of elasto-plastic compression of pillars accounting for material hardening and softening", Int. J. Rock Mech. Min. Sci. and Geomech. Abstr., 17. (1980)199-207.

148| Sandler, I., Wright, J.., "sumary of Strain-softening", Theorectical soundations for Large-Scale Computations of Nonlinear Material Behavior, DARPA-NSF Workshop, S. Nemat-Nasser, ed. Northwestern University, 1983.

$|49|$ Pietruszczak, st.. Mröz, 2., "Finite element analys is 
of deformations of stain-softening materials", Int. J. Num. Me th. Engrg., Vo1, 17, No. 3, (1981)327-334.

|50| Bazant, 2.P., Belyeschko, T.B., Chang, T.P., "Continuua Theory for Strain-S oftening", J. Engrg. Mech. Vol. 110 , No. 12 (1984)1666-1692.

\section{ACKNOWLE DGEMENT}

The support of CNPq and FINEP is gratefully acknowledged. 